Department of Medical Genetics, University of Antwerp, Universiteitsplein 1, 2610 Antwerp, Belgium $\mathrm{K}$ Janssens

E Van Hul

W Van Hul

Departments of

Human Genetics and

Paediatrics, Rambam

Medical Centre and

the Bruce Rappoport

Faculty of Medicine,

Technion, Israel

Institute of

Technology, Haifa,

Israel

R Gershoni-Baruch

R Brik

Department of

Rheumatology,

Hospital Clínic,

Barcelona, Spain

N Guañabens

Department of

Genetics, Biology, and

Biochemistry,

University of Torino,

Torino, Italy

$\mathrm{N}$ Migone

Department of Rheumatology, University Hospital of Brussels (VUB), Brussels, Belgium L A Verbruggen

Department of

Medicine and

Therapeutics,

University of Aberdeen

Medical School,

Fosterhill, Aberdeen,

UK

S H Ralston

Department of Medical Genetics, University Hospital of Brussels (VUB),

Brussels, Belgium $\mathrm{M}$ Bonduelle

Centre of Human Genetics, Institute of Pathology and

Genetics, Loverval, Belgium

L Van Maldergem

Department of Radiology, University Hospital of Antwerp, Antwerp, Belgium

F Vanhoenacker

Correspondence to: Dr W Van Hul,

vhul@uia.ua.ac.be

Revised version received 6 January 2000

Accepted for publication

7 January 2000

\title{
Localisation of the gene causing diaphyseal dysplasia Camurati-Engelmann to chromosome $19 \mathrm{q} 13$
}

Katrien Janssens, Ruth Gershoni-Baruch, Els Van Hul, Riva Brik, Nuria Guañabens,

Nicola Migone, Leon A Verbruggen, Stuart H Ralston, Maryse Bonduelle, Lionel Van Maldergem, Filip Vanhoenacker, Wim Van Hul

\begin{abstract}
Camurati-Engelmann disease, progressive diaphyseal dysplasia, or diaphyseal dysplasia Camurati-Engelmann is a rare, autosomal dominantly inherited bone disease, characterised by progressive cortical expansion and sclerosis mainly affecting the diaphyses of the long bones associated with cranial hyperostosis. The main clinical features are severe pain in the legs, muscular weakness, and a waddling gait. The underlying cause of this condition remains unknown.
\end{abstract}

In order to localise the disease causing gene, we performed a linkage study in a large Jewish-Iraqi family with 18 affected subjects in four generations. A genome wide search with highly polymorphic markers showed linkage with several markers at chromosome 19q13. A maximum lod score of $4.9(\theta=0)$ was obtained with markers D19S425 (58.7 cM, 19q13.1) and D19S900 (67.1 cM, 19q13.2). The disease causing gene is located in a candidate region of approximately $32 \mathrm{cM}$, flanked by markers D19S868 (55.9 cM, 19q13.1) and D19S571 (87.7 cM, 19q13.4). (F Med Genet 2000;37:245-249)

Keywords: Camurati-Engelmann disease; progressive diaphyseal dysplasia; chromosome 19q13; sclerosing bone dysplasia

Camurati-Engelmann disease (CED, MIM $131300)$ is a sclerotic bone disorder of unknown cause. This dysplasia was first described by Cockayne in $1920,{ }^{1}$ but Camurati $^{2}$ was the first to suggest its hereditary nature in 1922, describing a father and son, both with painful lower extremities, showing cortical thickening and sclerosis of the diaphyses on $x$ ray examination. In 1929, Engelmann ${ }^{3}$ reported a single case with muscular wasting and marked bone involvement. Neuhauser et $a l^{4}$ named this disease progressive diaphyseal dysplasia, emphasising the progressive nature of the hyperostosis and the involvement of the diaphyses. However, Kaftori et al later proposed that the disease should be renamed progressive bone dysplasia since the metaphyses, skull, and even the vertebrae can be affected. Currently, the eponym Camurati-Engelmann disease is the most widely accepted, although recently the International Working Group on Constitutional Disease of Bone suggested naming this condition diaphyseal dysplasia Camurati-Engelmann. ${ }^{6}$

Besides muscle weakness, claudication, and severe pain in the legs, which affect the majority of CED patients, other observed clinical symptoms are easy fatiguability, reduced muscle mass, general weakness, exophthalmos, facial paralysis, hearing difficulties, and loss of vision. ${ }^{7}$ The first symptoms of the disease are mostly detected before the age of 30, but in many cases may be present in the first decade of life.

Routine biochemical parameters of bone and mineral metabolism, such as serum calcium and alkaline phosphatase, are usually normal. ${ }^{8}$ A study by Hernández et $a l^{9}$ in four CED patients, however, showed increases in several markers of bone turnover, such as bone alkaline phosphatase, serum osteocalcin, and crosslinked N-telopeptides of type I collagen.

Radiologically, CED is characterised by fusiform thickening of the cortex in the diaphyseal portions of the long bones. In some cases the metaphyses are affected, ${ }^{10}{ }^{11}$ but the epiphyses are typically spared. ${ }^{12}$ The medullary canals may be narrowed as shown in fig 1 . The distribution of the lesions in the skeleton is symmetrical. In decreasing order of frequency, the tibia, femur, fibula, humerus, ulna, and radius are affected. Usually, sclerotic changes are found at the base of the skull with occasional involvement of the cranial vault and the facial bones.

There is no specific treatment for CED, but glucocorticoids can alleviate fatigue, limb pain, and muscle weakness. They do not alter the radiological signs such as thickened long bones and have no effect on muscle mass. The effect of the drug is only temporary; when the treatment ends, the symptoms recur.

The prevalence of CED is very low; so far only 170 patients have been described. Multiple family studies ${ }^{71314}$ have shown the autosomal dominant mode of inheritance of CED although a few isolated patients have been reported.

In order to localise the gene responsible for CED, we performed a genetic linkage study on an Israeli family of Jewish-Iraqi origin. This family was previously ascertained and studied by Naveh et $a l^{13}$ and is one of the largest families published.

\section{Methods}

SUBJECTS

Blood samples were collected from an extended four generation Jewish-Iraqi family. Twenty eight family members were clinically 


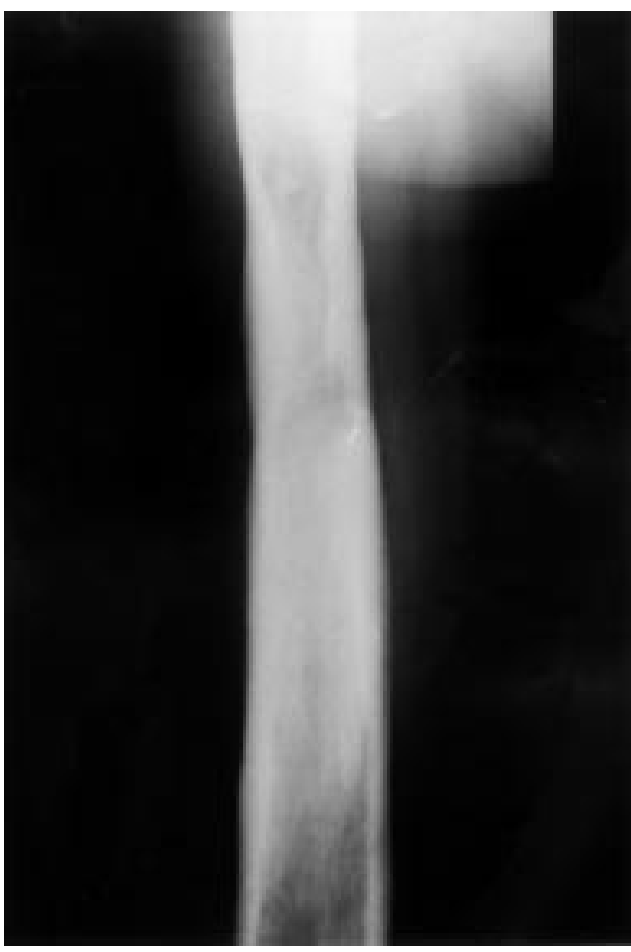

Figure $1 X$ ray of the diaphysis of the left femur of an adult CED patient. Fusiform thickening of the cortex is observed in the diaphyseal portion of the femur. The medullary canal is narrowed.

examined and 25 of these were, after signing informed consent, willing to participate in the study by the donation of a blood sample. The diagnosis was made on clinical grounds by the presence of bone pain, a waddling gait, and muscular weakness. In most cases the diagnosis was confirmed by radiological examination. Asymptomatic subjects who did not undergo radiological examination were considered as diagnosis unknown.

\section{GENOTYPING}

Genomic DNA was isolated from fresh leucocytes using standard techniques. The Cooperative Human Linkage Centre Human Screening Set (Weber version 6) was used for a genome wide linkage study. This set contains 391 fluorescently labelled, highly polymorphic markers covering the entire human genome with an average spacing of $10 \mathrm{cM}$. The markers were analysed by use of an automated DNA sequencing apparatus (Applied Biosystems model 377). Extra markers for regions of interest were chosen from the Généthon Genetic Linkage Map. ${ }^{15}$ These were analysed using either radioactive isotope labelling or a 5'-IRD label. In the first protocol, radioactive end labelling of one oligonucleotide was performed before PCR using T7 polynucleotide kinase. Amplification products were separated according to size on a $6 \%$ polyacrylamide gel and analysed after autoradiography. In the alternative approach, one of the primers is synthesised with an M13 forward or reverse sequence at the 5 ' end. An IRD labelled ( $800 \mathrm{~nm}$ ) M13 primer is included in the PCR reaction and is incorporated from the second cycle, thus labelling the PCR product. Gel electrophoresis and pattern visualisation were performed using a LI-COR model 4200 DNA analyser (NEN).

LINKAGE ANALYSIS

Two point lod scores were calculated by use of MLINK (version 5.1). ${ }^{16}$ The disease frequency was set at 1/1 000000 . An autosomal dominant mode of inheritance was assumed with a disease penetrance of $100 \%$. Allele frequencies were set at $1 / \mathrm{n}$ with $\mathrm{n}$ being the number of alleles detected.

\section{Results}

CLINICAL AND RADIOLOGICAL EXAMINATION OF THE FAMILY MEMBERS

In our current update of this family, we diagnosed 18 subjects as being affected with CED (fig 2). Both sexes were almost equally affected with CED (eight women and 10 men). Their diagnoses were mainly based on the presence of clinical symptoms. The most frequent symptoms were muscle weakness, reduced muscle mass, a waddling gait, exophthalmos, and thickening of the long bones. A few people (II.1, III.4, III.6, and III.9) were asymptomatic but based on the presence of affected descendants they must be obligate carriers. II.1 (currently 64 years old), for example, has no symptoms, while her daughter (III.1) suffers from pain and claudication. III.4, III.6, and III.9 all have a child showing typical symptoms of CED, including a waddling gait, inability to run quickly, and muscle pains. For two of these asymptomatic carriers (III.4 and III.6), radiological examination confirmed the affected status. Because of the presence of clinically asymptomatic gene carriers, all at risk subjects with no clinical symptoms and without radiological survey were assigned an unknown affected status (II.1, III.9, III.14, III.17, III.20, IV.6, and IV.7).

The onset of the disease in this family varied, but was more common in childhood. There is considerable variability in the symptoms and clinical signs of the affected subjects; some patients are asymptomatic while III.15 and III.18, only teenagers, already complain of severe pains and muscle weakness in the lower extremities. Radiological examination showed symmetrical involvement of the long bones.

\section{LINKAGE ANALYSIS}

Linkage analysis in the Israeli family throughout the whole genome with markers of the Weber set excluded more than $70 \%$ of the human genome with lod scores below -2 . D19S900 (19q13.2) was the marker most suggestive of linkage. To confirm these initial data and to delineate the candidate region, extra markers from this region were genotyped. The highest lod score of $4.9(\theta=0)$ was obtained with markers D19S425 and D19S900 (table 1). Four other markers in the same region (D19S416, D19S223, D19S879, and D19S867) also showed a lod score above 4 $(\theta=0)$. Besides these, three more markers (D19S876, D19S412, and D19S606) appeared to be free of recombination (table 1, fig 2). Together, these markers indicated a candidate region of approximately $32 \mathrm{cM}$. The 


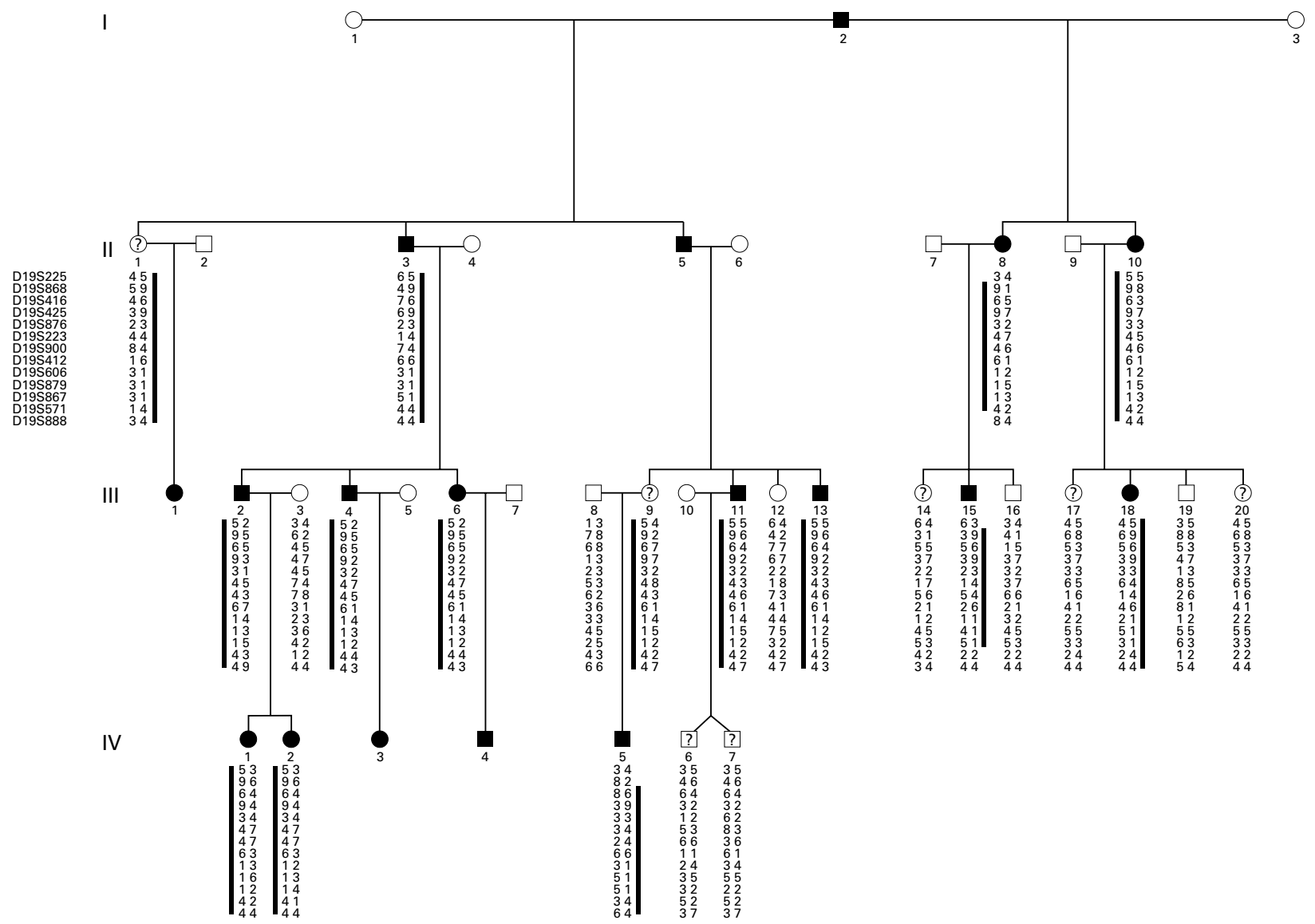

Figure 2 Pedigree reconstruction of the four generation fewish-Iraqi CED family. Question marks represent subjects with an unknown affected status. Manually constructed haplotypes for the chromosome 19 markers are shown below the symbols. The haplotype consists of alleles from 13 marker loci. The black bars represent the haplotype that cosegregates with the disease.

Table 1 Two point lod scores $(Z)$ at recombination fraction $(\theta)$ between CED and 13 markers from chromosome 19q13

\begin{tabular}{llllllll}
\hline & \multicolumn{7}{c}{ Lod score $(Z)$ at recombination fraction $(\theta)$} \\
\cline { 2 - 8 } & 0.0 & 0.01 & 0.05 & 0.1 & 0.2 & 0.3 & 0.4 \\
\hline D19S225 & $-\infty$ & -0.02 & 1.15 & 1.45 & 1.40 & 1.05 & 0.57 \\
D19S868 & $-\infty$ & 2.83 & 3.22 & 3.12 & 2.57 & 1.82 & 0.95 \\
D19S416 & 4.83 & 4.75 & 4.43 & 4.00 & 3.10 & 2.12 & 1.08 \\
D19S425 & 4.92 & 4.84 & 4.51 & 4.09 & 3.18 & 2.19 & 1.13 \\
D19S876 & 2.30 & 2.28 & 2.16 & 1.96 & 1.47 & 0.93 & 0.41 \\
D19S223 & 4.74 & 4.66 & 4.33 & 3.91 & 3.00 & 2.02 & 0.97 \\
D19S900 & 4.90 & 4.82 & 4.50 & 4.08 & 3.17 & 2.19 & 0.13 \\
D19S412 & 3.02 & 2.97 & 2.73 & 2.41 & 1.73 & 1.03 & 0.40 \\
D19S606 & 3.28 & 3.25 & 3.10 & 2.86 & 2.26 & 1.56 & 0.79 \\
D19S879 & 4.36 & 4.28 & 3.96 & 3.54 & 2.66 & 1.72 & 0.78 \\
D19S867 & 4.37 & 4.29 & 3.96 & 3.54 & 2.66 & 1.72 & 0.76 \\
D19S571 & $-\infty$ & 0.47 & 1.03 & 1.15 & 1.04 & 0.76 & 0.40 \\
D19S888 & $-\infty$ & -0.10 & 0.50 & 0.67 & 0.67 & 0.49 & 0.26 \\
\hline
\end{tabular}

proximal key recombinant can be seen with marker D19S868 (19q13.1) which recombines in IV.5. On the distal side, D19S571 (19q13.4) recombines in III.15 (fig 3).

\section{Discussion}

Bone is a dynamic tissue, which is constantly remodelled throughout life by two processes, bone formation and bone resorption. The balance of these processes is under control of both systemic and local factors. Disruption of this balance can cause a diverse spectrum of pathological conditions. At one end of the spectrum, we find the conditions with decreased bone density, of which osteoporosis is the most frequent. At the other end, there is a set of mainly rare, inherited conditions characterised by increased bone density. CED is an example of these sclerosing bone dysplasias.

The great majority of sclerosing bone dysplasias have not yet been characterised at the molecular level, with the exceptions of carbonic anhydrase II, which causes osteopetrosis with renal tubular acidosis, ${ }^{17}$ and of the cathepsin K gene which underlies pyknodysostosis. ${ }^{18}$ However, genetic linkage studies in extended pedigrees have recently localised disease causing genes for several of these conditions: An autosomal dominant and a recessive form of osteopetrosis were assigned to $1 \mathrm{p} 21$ and $11 \mathrm{q} 13$ respectively, ${ }^{19}{ }^{20}$ whereas two related conditions, van Buchem disease and sclerosteosis, both presenting as endosteal hyperostoses, were assigned to $17 \mathrm{q} 12-\mathrm{q} 21 .^{2122}$

Taking into account the progress of the Human Genome Project, the identification of other genes responsible for sclerosing bone dysplasias can be expected soon.

CED presents in most cases with an autosomal dominant mode of inheritance but some so called skipped generations, in which carriers show no radiological abnormalities, have been described. ${ }^{23}$ Sparkes and Graham, ${ }^{7}$ for example, presented the case of a severely affected subject with asymptomatic parents and grandparents showing no definite radiological abnormalities. However, six additional cases of CED were discovered in the same 


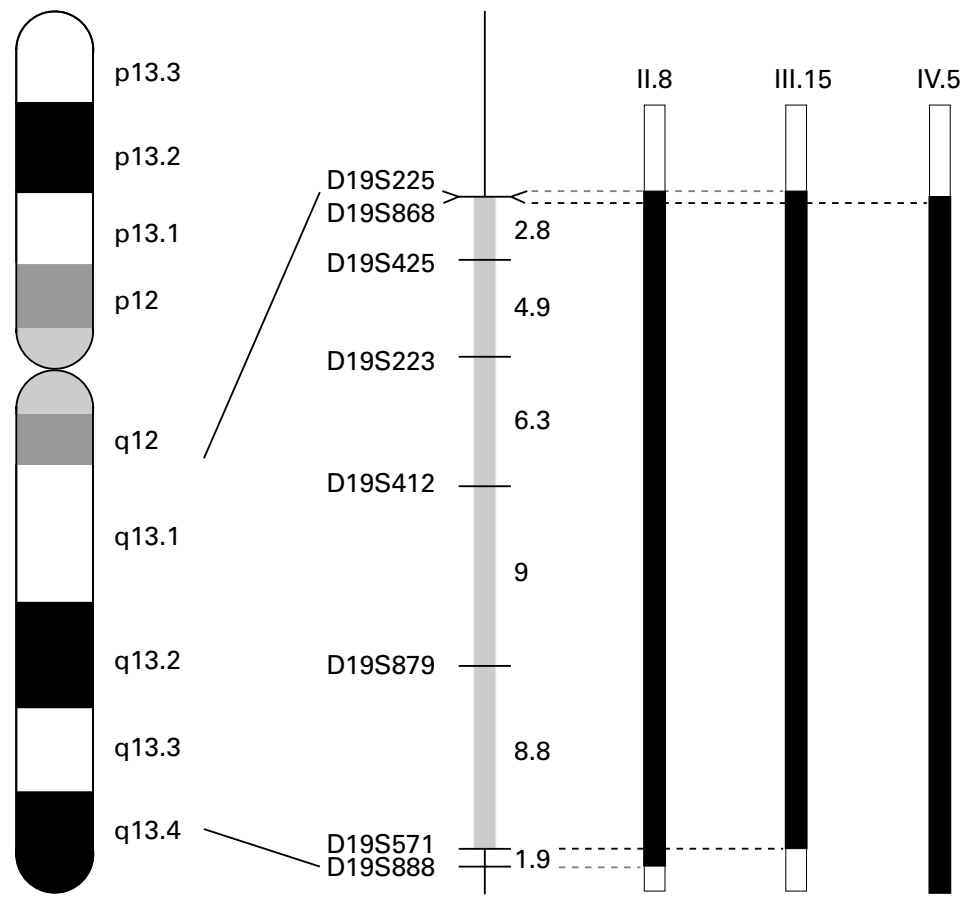

Figure 3 Representation of chromosome 19 with an enlargement of the candidate region $19 q 13$ and its delineation by the key recombinants. The recombination event in IV.5 between D19S868 and the CED gene localises the gene distal to D19S868. The recombination event in III. 15 indicates that the CED gene must be located proximal to D19S571.

family rejecting the isolated status of this case. In our family, non-penetrance was observed in several cases based on clinical examination, but, when available, radiological examination allowed us to confirm the affected status. The progression of the disease is highly unpredictable; stages of progression can alternate with quiescent and inactive stages. Onset of the disease seems to be more common in childhood, as is the case in our family.

So far, the cause of CED is unknown. Since CED is a progressive disease, the gene responsible is unlikely to be involved in bone development but rather is most probably involved in the regulation of bone metabolism and bone turnover throughout life. During skeletal growth and ageing, new bone is laid down on the periosteal surfaces of long bones and undergoes a process of maturation to form cancellous bone of the bone cortex. Simultaneously, bone is removed from the endosteal surfaces to create the marrow cavity. Both of these processes appear to be abnormal in CED, where the formation of periosteal bone is disorganised and the removal of endosteal bone is abnormal. In view of this, identification of the disease causing gene in CED will provide new insight into the mechanisms by which normal bone remodelling occurs and may also represent a therapeutic target for the prevention of osteoporosis or the healing of bone fractures.

The candidate region we have identified is large and contains several known genes. Among others, we feel that at least four genes need further consideration. These are "nuclear factor of kappa light polypeptide gene enhancer in B cells inhibitor, beta" (NFKBIB on 19q13.1), human proto-oncogene BCL3 gene (19q13.1), transforming growth factor beta-1 (TGF $\beta-1$ on $19 \mathrm{q} 13.1$ ), and latent transforming growth factor beta binding protein-4 (LTBP-4 on 19q13.1-19q13.2). NFKBIB encodes the I $\kappa \mathrm{B} \beta$ protein, an inhibitor of $\mathrm{NF \kappa B}$. NFאB regulates the expression of a variety of genes involved in immune and inflammatory responses, but also plays a role in the generation and function of osteoclasts. ${ }^{24}$ BCL3 has a similar function. ${ }^{25}$ Transforming growth factor- $\beta$ (TGF $\beta-1)$ is a multifunctional growth factor in bone with effects on cells of the osteoclast and osteoblast lineage, ${ }^{26}$ whereas LTBP-4 is a member of the LTBP-fibrillin family of proteins which are needed for the secretion and folding of TGF $\beta-1 .^{27}$ It is of interest that glucocorticoids are known to regulate the activity of both $\mathrm{Nf \kappa B}{ }^{28}$ and TGF $\beta-1,{ }^{29}$ which would make $N F K B I B, B C L 3, T G F \beta-1$, and $L T B P-4$ strong positional candidate genes.

In conclusion, the localisation of the disease causing gene for CED presented here will most probably accelerate its characterisation. This might result in a better understanding of the underlying pathogenesis and might contribute to our general knowledge of bone metabolism.

This study was supported by a concerted action grant from the University of Antwerp to WVH. KJ is holder of a predoctoral position with the Flemish FWO (Fonds voor Wetenschappelijk position with the Flemish FWO (Fonds voor Wetenschappelijk Onderzoek). SHR is supported by the Arthritis Research Cam-
paign ICAC award and a cooperative group grant from the Medical Research Council of the UK.

1 Cockayne EA. Case for diagnosis. Proc $R$ Soc Med 1920;13:132-6.

2 Camurati $M$. Di un raro caso di osteite simmetrica ereditaria degli arti inferiori. Chir Organi Mov 1922;6:662-5.

3 Engelmann G. Ein fall von ostheopathia hyperostotica (sclerotisans) multiplex infantilis. Forschr Gebiete Röntgenstr Nuklearmed 1929;39:1101-6.

4 Neuhauser EB, Schwachman H, Wittenborg M, Cohen J. Progressive diaphyseal dysplasia. Radiology 1948;51:11-22.

5 Kaftori JK, Kleinhaus U, Naveh Y. Progressive diaphyseal dysplasia (Camurati-Engelmann): radiographic follow-up and CT findings. Radiology 1987;164:777-82.

6 International Working Group on Constitutional Disease of Bone. International nomenclature and classification of osteochondrodysplasias (1997). Am f Med Genet 1998;79: 376-82.

7 Sparkes RS, Graham CB. Camurati-Engelmann disease. Genetics and clinical manifestations with a review of the literature. F Med Genet 1972;9:73-85.

8 Hanson W, Parnes LS. Vestibular nerve compression in Camurati-Engelmann disease. Ann Otol Rhinol Laryngol 1995;104:823-5.

9 Hernández MV, Peris P, Guañabens N, et al. Biochemical markers of bone turnover in Camurati-Engelmann disease: a report on four cases in one family. Calcif Tissue Int 1997; 61:48-51.

10 Brat HG, Hamoir X, Matthijs P, Lambin P, Van Campenhoudt M. Camurati-Engelmann disease: a late and sporadic case with metaphyseal involvement. Eur Radiol 1999;9:159-62.

11 Hoeffel JC, Mainard L, Leyder B. Camurati-Engelmann disease. A case report. Eur Radiol 1999;9:1932-3.

12 Greenspan A. Sclerosing bone dysplasias - a target-site approach. Skeletal Radiol 1991;20:561-83.

13 Naveh Y, Kaftori JK, Alon U, Ben-David J, Berant M. Progressive diaphyseal dysplasia: genetics and clinical and gressive diaphyseal dysplasia: genetics and clinical
radiologic manifestations. Pediatrics 1984;74:399-405.

14 Saraiva JM. Progressive diaphyseal dysplasia: a threegeneration family with markedly variable expressivity. $A m \mathcal{F}$ Med Genet 1997;71:348-52.

15 Dib C, Fauré S, Fizames C, et al. A comprehensive genetic map of the human genome based on 5,264 microsatellites. Nature 1996;380:152-4.

16 Lathrop GM, Lalouel JM. Easy calculations of lod scores and genetic risks on small computers. Am f Hum Genet 1984;36:460-5.

17 Sly WS, Hewett-Emmett D, Whyte MP, Yu YS, Tashian RE. Carbonic anhydrase II deficiency identified as the primary defect in the autosomal recessive syndrome of osteopetrosis with renal tubular acidosis and cerebral calcification. Proc Natl Acad Sci USA 1983;9:2752-6.

18 Gelb BD, Shi GP, Chapman HA, Desnick RJ. Pycnodysostosis, a lysosomal disease caused by cathepsin K deficiency.
tersos. Science 1996;273:1236-8. 
19 Van Hul W, Bollerslev J, Gram J, et al. Localization of a gene for autosomal dominant osteopetrosis (Albers-Schönberg disease) to chromosome 1p21. Am F Hum Genet 1997;61. 363-9.

20 Heaney C, Shalev H, Elbedour K, et al. Human autosomal recessive osteopetrosis maps to $11 \mathrm{q} 13$, a position predicted by comparative mapping of the murine osteosclerosis (oc) mutation. Hum Mol Genet 1998;7:1407-10.

21 Van Hul W, Balemans W, Van Hul E, et al. Van Buchem disease (hyperostosis corticalis generalisata) maps to chromosome 17q12-q21. Am 7 Hum Genet 1998;62:391-9.

22 Balemans W, Van Den Ende J, Paes-Alves AF, et al. Localization of the gene for sclerosteosis to the van Buchem disease-gene region on chromosome 17q12-q21. Am Hum Genet 1999;64:1661-9.

23 Whyte MP. Heritable metabolic and dysplastic bone diseases. Endocrinol Metab Clin North Am 1990;19:133-73.

24 Boyce BF, Xing L, Franzoso G, Siebenlist U. Required and nonessential functions of nuclear factor-kappa B in bone cells. Bone 1999;25:137-9.
25 Wulczyn FG, Naumann M, Scheidereit C. Candidate proto-oncogene bcl-3 encodes a subunit-specific inhibitor of transcription factor NF-kappa-B. Nature 1992;358:5979.

26 Canalis E, McCarthy T, Centrella M. Growth factors and the regulation of bone remodeling. $\mathcal{F}$ Clin Invest 1988;81: 277-81.

27 Saharinen J, Taipale J, Monni O, Keski-Oja J. Identification and characterization of a new latent transforming growth factor-beta-binding protein, LTBP-4. F Biol Chem 1998; 273:18459-69.

28 Bodine PV, Harris HA, Komm BS. Suppression of ligand-dependent estrogen receptor activity by boneresorbing cytokines in human osteoblasts. Endocrinology 1999;140:2439-51.

29 Oursler MJ, Riggs BL, Spelsberg TC. Glucocorticoidinduced activation of latent transforming growth factorbeta by normal human osteoblast-like cells. Endocrinology 1993;133:2187-96. 